\title{
DESAIN MEJA PENJAJA IKAN HIGIENIS UNTUK PASAR IKAN DI PELABUHAN AWANG LOMBOK TENGAH
}

\author{
DESIGN OF TABLE SALE FISH HYGIENIC FOR FISH MARKET IN AWANG PORT CENTRAL \\ $L O M B O K$
}

\author{
Imam Taukhid, Amin Pamungkas, Daud S. A. Sianturi dan Donal Daniel \\ Pusat Pengkajian dan Perekayasaan Teknologi Kelautan dan Perikanan, Balitbang KP \\ Jalan Pasir Putih 1, Ancol Timur Jakarta, 14430 \\ E-mail:imam_t@kkp.go.id
}

Diterima tanggal: 5 Mei 2014, diterima setelah perbaikan: 1 Juli 2014, disetujui tanggal: 14 Juli 2014

\begin{abstract}
ABSTRAK
Kemunduran mutu kesegaran ikan yang terjadi di pasar-pasar ikan adalah akibat dari penanganan yang tidak tepat. Wadah penjaja yang seadanya, serta lingkungan yang tidak higienis. Solusi untuk mengatasi hal ini dapat menerapkan teknik refrigerasi. Dalam mendesain sistem refrigerasi harus mengetahui beban pendinginan untuk memudahkan dalam pemilihan peralatan sistem refrigerasi. Sistem refrigerasi ini menggunakan refrigeran R134a. Desain meja penjaja untuk kebutuhan pasar ikan di pelabuhan Lombok Tengah direncanakan memiliki kapasitas sebesar satu meter kubik dan mampu menampung ikan sebanyak $250 \mathrm{~kg}$ dengan daya sebesar $3 \mathrm{~kW}$. Dari analisis beban pendinginan yang dilakukan, maka diperoleh nilai COP sebesar 3,65.
\end{abstract}

Kata kunci: Awang, meja higienis, refrigerasi, COP

ABSTRACT

The decrease of fish freshness, quality occurred in the fish markets is a result of improper handling. The appropriate container, as well as unhygienic environment. The solution to overcome this is by applying refrigeration techniques. In designing the refrigeration system the cooling load must be known in the selection of equipment to the refrigeration system. The refrigeration system uses R134a. This device is designed for the needs of the fish market in Central Lombok harbor with a capacity of one meter cubic and a fish mass of $250 \mathrm{~kg}$, it takes energy of $3 \mathrm{~kW}$. From cooling load analysis performed the COP value of 3.65 is obtained.

Keywords: Awang, hygienic table, refrigeration, $C O P$

\section{PENDAHULUAN}

Kondisi pelabuhan-pelabuhan perikanan di Indonesia pada umumnya adalah kotor, bau, dan kurang higienis, hal ini terjadi juga di Pelabuhan Perikanan di Lombok Tengah dimana nelayannelayan disana menjual ikan hasil tangkapan pada wadah-wadah styrofoam dengan teknik pengawetan yang sederhana. Penggunaan wadah yang berulang kali dan kondisi pasar yang terbuka akan sangat mempengaruhi kualitas ikan hasil tangkapan yang dijual, disebabkan ikan adalah jenis pangan daging yang cepat membusuk apabila tidak diawetkan dengan baik, apalagi Indonesia merupakan wilayah tropis yang menyebabkan bakteri penyebab kemunduran mutu ikan cepat berkembang. Masalah utama yang dihadapi dalam penanganan ikan adalah penurunan mutu ikan yang cepat akibat penanganan yang tidak tepat (Suherman dan Gunawan, 1999).

Masih tingginya kerusakan produk perikanan tangkap disebabkan pengetahuan nelayan pada umumnya masih rendah tentang tata cara penanganan ikan dari saat menangkap sampai di pendaratan ikan (Sjarif, Suwardiyono \& Gautama, 2010). Padahal, sebagian besar produk ikan segar tujuan ekspor adalah berasal dari nelayan tradisional yang menggunakan kapal kayu dan es sebagai media pengawetan ikan (Daniel, 2011). 
Dikenal ada tiga cara teknik untuk mempertahankan kesegaran ikan, yaitu dengan es, dengan udara dingin (refrigerasi) dan dengan air dingin (chiller) (Ilyas, 1983). Cara yang umum dipakai oleh pedagang eceran di pasar ikan dan nelayan tradisional pada palka-palka kayu adalah teknik pengesan, dinilai kurang higienis.

Di dalam penelitian ini, penulis bermaksud merubah cara-cara pengawetan ikan dengan teknik refrigerasi. Pasar ikan di Pelabuhan Awang adalah pasar yang masih baru, oleh karena itu diharapkan meja penjaja higienis ini akan menjadi pelopor pemanfaatan fasilitas pasar yang lebih modern. Teknik refrigerasi yaitu suatu teknik untuk menyerap kalor atau panas dari suatu benda atau ruang untuk menurunkan temperatur yang lebih rendah pada level yang diinginkan. Tujuannya adalah untuk menghambat laju pertumbuhan bakteri penyebab kemunduran mutu ikan, menjaga tekstur sehingga tetap segar. Umumnya, sistem refrigerasi terdiri dari kompresor, kondensor, katup expansi dan evaporator (Tampubolon dan Samosir, 2005). Teknik ini membutuhkan energi yang disuplai ke kompresor dan setara dengan energi panas yang diserap oleh refrigeran yang mengalir melalui evaporator. Siklus refrigerasi sederhana dapat dilihat pada Gambar 1.

Dari penelitian yang pernah dilakukan untuk mengetahui laju pendinginan kondensor diketahui bahwa semakin tinggi laju pendinginan maka laju aliran massa refrigeran, kapasitas pendinginan dan COP (Coefficient of Performance) juga semakin meningkat (Prasetya dan Putra, 2013). COP adalah besaran yang menunjukkan unjuk kerja mesin pendingin, didefinisikan sebagai perbandingan antara kapasitas pendinginan dengan power input (Handoyo dan Lukito, 2002). Hal ini berkaitan dengan jenis beban yang akan didinginkan, karena pemilihan kapasitas kompresor ditentukan dari perhitungan beban pendingin (Radha, Sarada dan Rajagopal, 2012). Dalam penelitian ini dengan beban utamanya adalah ikan dan air yang harus didinginkan pada temperatur $-2{ }^{0} \mathrm{C}$. Nilai COP juga dapat ditentukan dari rasio tekanan antara kondensor dan evaporator $(\mathrm{Pc} / \mathrm{Pe})$ dengan mengalirkan refrigeran dari kondensor ke evaporator melalui pipa kapiler dengan variasi diameter (Soegeng, 2009). Sedangkan Marwan (2005) melakukan penelitian untuk meningkatkan COP dengan melilitkan pipa kapiler pada line suction meningkatkan COP sistem dan waktu yang diperlukan untuk menurunkan $1{ }^{0} \mathrm{C}$ larutan air garam semakin lama untuk temperatur yang makin rendah. Selain itu, perlu diketahui besaran-besaran seperti kalor jenis (Cp), massa benda (m), temperatur ruangan dan temperatur pendinginan (T1 dan T2).

Banyaknya kalor $(\mathrm{Q})$ yang harus diambil dari suatu benda yang akan diturunkan temperaturnya, inilah yang menentukan energi (Joule) untuk produk ikan yang didinginkan. Selain itu, faktor-faktor lain yang ikut mempengaruhi adalah nilai konduktifitas termal dinding wadah yang digunakan.

Sehingga dari uraian di atas, penelitian ini bertujuan untuk merancang meja penjaja ikan higienis di pasar ikan Pelabuhan Awang serta mengetahui kebutuhan peralatan sistem refrigerasinya. Meja penjaja ini akan dimanfaatkan oleh penjual ikan eceran di pasar ikan untuk menggantikan cara-cara lama menggunakan teknik pengesan yang terkenal menghasilkan lingkungan yang basah dan bau.

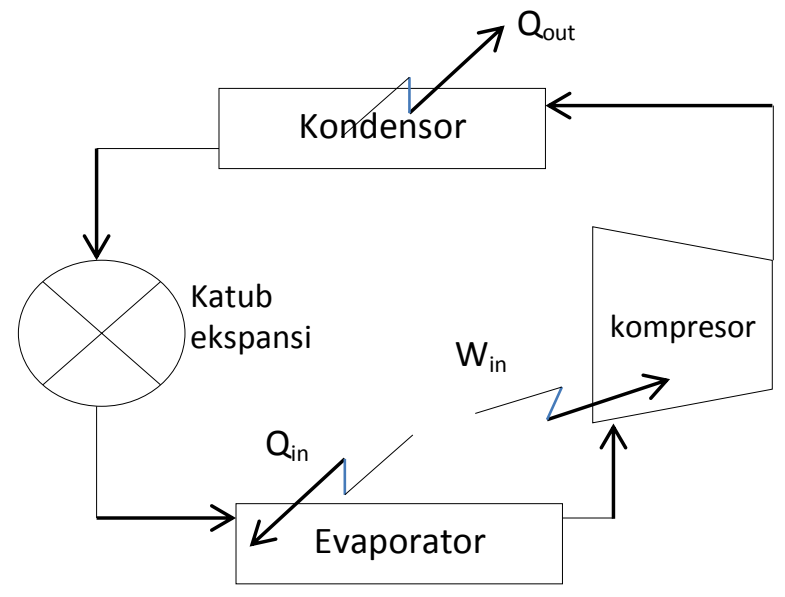

Gambar 1. Siklus refrigerasi kompresi uap standar

Figure 1. A vapor compression refrigeration cycles Sumber: Tampubolon dan Samosir, 2005

\section{BAHAN DAN METODE}

Langkah yang dilakukan dalam perhitungan desain meja penjaja ikan higienis adalah studi teoritis memanfaatkan beberapa tool pengolah data dikarenakan tidak dilakukan pengukuran langsung karena kendala peralatan ukur yang tidak tersedia. Adapun penentuan komponen sistem refrigerasi 
diambil dari brosur-brosur produk setelah dihitung menggunakan software. Parameter-parameter input yang digunakan mencakup input data temperatur air, temperatur ruangan, temperatur gas masuk evaporator, temperatur gas masuk kondensor, energi pendinginan dan jenis refrigeran.

Untuk mendesain sebuah sistem refrigerasi terlebih dahulu harus dihitung kebutuhan energi untuk mendinginkan beban. Meja penjaja ikan higienis akan ditempatkan di Pelabuhan Perikanan di Teluk Awang Lombok Tengah. Untuk merancang meja penjaja maka dilakukan tahap-tahap:

a. Penentuan beban pendinginan

Beban yang akan didinginkan yaitu:

$\checkmark$ Air tawar dan

$\checkmark$ Ikan kembung

Dimensi meja penjaja dari kebutuhan di lapangan diperoleh dimensi

$\begin{array}{ll}\checkmark \text { Panjang } & : 4000 \mathrm{~mm} \\ \checkmark \text { Lebar } & : 800 \mathrm{~mm} \\ \checkmark \text { Tinggi bak pendingin } & : 300 \mathrm{~mm} \\ \checkmark \text { Tinggi total } & : 800 \mathrm{~mm} \\ \checkmark \text { Volume total bak } & : 1000 \mathrm{~m}^{3}\end{array}$

Bak dibagi ke dalam 16 (enam belas) bagian bakbak kecil untuk mendinginkan ikan (Gambar 2).

b. Menghitung beban pendinginan atau energi yang dilepaskan selama proses pendinginan dihitung dengan menggunakan persamaan :

$$
\mathrm{Q}=\mathrm{m} \cdot \mathrm{C}_{\mathrm{p}} \cdot \Delta \mathrm{T}
$$

dimana :

$$
\begin{array}{ll}
\mathrm{m} & =\text { massa ikan dan air } \\
\mathrm{C}_{\mathrm{p}} & =\text { panas spesifik air dan ikan } \\
\Delta \mathrm{T} & =\text { beda temperatur awal dan akhir } \\
\text { massa ikan } & =250 \mathrm{~kg} \\
\text { massa air } & =1000 \mathrm{~kg} \\
\mathrm{C}_{\mathrm{p}} & =\text { ikan kembung } 4978 \mathrm{~J} / \mathrm{Kg}^{0} \mathrm{C} \\
\mathrm{C}_{\mathrm{p}} & =\text { air } 4200 \mathrm{~J} / \mathrm{Kg}^{0} \mathrm{C}
\end{array}
$$

Dari hasil perhitungan, energi untuk mendinginkan ikan $=3 \mathrm{~kW}$

c. Data-data awal untuk menghitung energi pendinginan beban adalah :

$\checkmark$ Temperatur air untuk mengisi bak: $2{ }^{0} \mathrm{C}$

$\checkmark$ Temperatur ruangan

$\checkmark$ Temperatur evaporator

: $30{ }^{\circ} \mathrm{C}$

$\checkmark$ Temperatur kondensor

$:-2{ }^{\circ} \mathrm{C}$

$\checkmark$ Beban pendinginan

$: 45^{\circ} \mathrm{C}$

$\checkmark$ Refrigeran

$: 3 \mathrm{~kW}$

$\checkmark$ Waktu operasi meja
$: \mathrm{R}-134 \mathrm{a}$

: $12 \mathrm{jam}$
Dalam penelitian ini, beban pendinginan diperoleh dengan asumsi bak berisi air dengan volume 1000 $\mathrm{m}^{3}$ dan ikan berjenis ikan kembung dengan koefisien panas ikan $4978 \mathrm{~J} / \mathrm{Kg}{ }^{\circ} \mathrm{C}$.

$\checkmark$ Berat ikan adalah $250 \mathrm{Kg}$

$\checkmark$ Berat air adalah $1000 \mathrm{Kg}$

d. Penentuan besaran evaporator

Untuk pemilihan evaporator menggunakan Guntner 2013 dengan parameter input data:

$$
\begin{array}{ll}
\checkmark \text { kapasitas pendinginan } & =3 \mathrm{~kW} \\
\checkmark \text { jenis refrigeran } & =\mathrm{R} 134 \mathrm{a} \\
\checkmark \text { temperatur evaporator } & =-2{ }^{0} \mathrm{C} \\
\checkmark \text { superheating dan subcooling } & =5 \mathrm{~K} \text { (di } \\
\quad \text { sarankan) } & \\
\checkmark \text { temperatur masuk evaporator } & =11{ }^{0} \mathrm{C} \\
\checkmark \text { tekanan } & =1013 \mathrm{mbar}
\end{array}
$$

Setelah itu harus dipilih produk evaporator dari brosur.

\section{e. Penentuan besaran kondensor}

Untuk pemilihan kondensor menggunakan Guntner 2013 dengan memasukkan

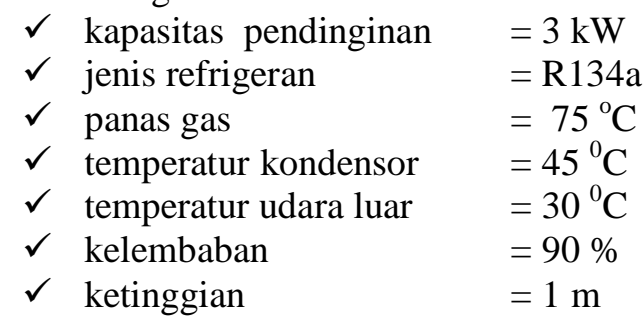

Setelah itu harus dipilih produk kondensor dari brosur.

\section{f. Penentuan besaran kompresor}

Perhitungan energi kalor (Joule atau Watt) yang diperlukan untuk menurunkan temperatur ikan sebesar $2{ }^{\circ} \mathrm{C}$ dapat dihitung dengan menjumlahkan pengaruh dari beban ikan dan beban dari air. Penentuan jenis kompresor dengan menggunakan DanfossRs +3 . Dari besarnya energi pendinginan ini maka besaran kompresor dapat dipilih di pasarandengan memasukkan parameter :

$\begin{array}{rlrl}\checkmark & \text { kompresor } & & =\text { hermetik } \\ \checkmark & \text { kapasitas pendinginan } & & =3 \mathrm{~kW} \\ \checkmark & \text { jenis refrigeran } & & \mathrm{R} 134 \mathrm{a} \\ \checkmark & \text { frekuensi listrik } & & =50 \mathrm{~Hz} \\ \checkmark & \text { Tegangan listrik } & =220 \mathrm{Volt} \\ \checkmark & \text { subcooling } & =5 \mathrm{~K} \\ \checkmark & \text { evaporatorsuper heat } & =5 \mathrm{~K} \\ \checkmark & \text { temperatur evaoprator } & =-2{ }^{\circ} \mathrm{C} \\ \checkmark \text { temperatur kondensor } & =45{ }^{\circ} \mathrm{C}\end{array}$


g. Penentuan diameter pipa kapiler

Untuk pemilihan pipa kapiler menggunakan Danfoss DanCap dengan memasukkan parameter data sebagai berikut:

$$
\begin{array}{lll}
\checkmark & \text { Jenis refrigeran } & =\mathrm{R} 134 \mathrm{a} \\
\checkmark & \text { Beban panas dari sistem } & =181,9 \mathrm{Btu} / \mathrm{jam} \\
\checkmark & \text { Temperatur evaporator } & =-2{ }^{\circ} \mathrm{C} \\
\checkmark & \text { Temperatur kondensor } & =45^{\circ} \mathrm{C} \\
\checkmark & \text { Temperatur balik refrigeran } & \\
& \text { ke kompresor } & =11^{\circ} \mathrm{C}
\end{array}
$$

\section{HASIL DAN PEMBAHASAN}

Hasil analisis dengan menggunakan AutoCAD desain meja penjaja ikan higienis didesain seperti pada Gambar 2 berikut.

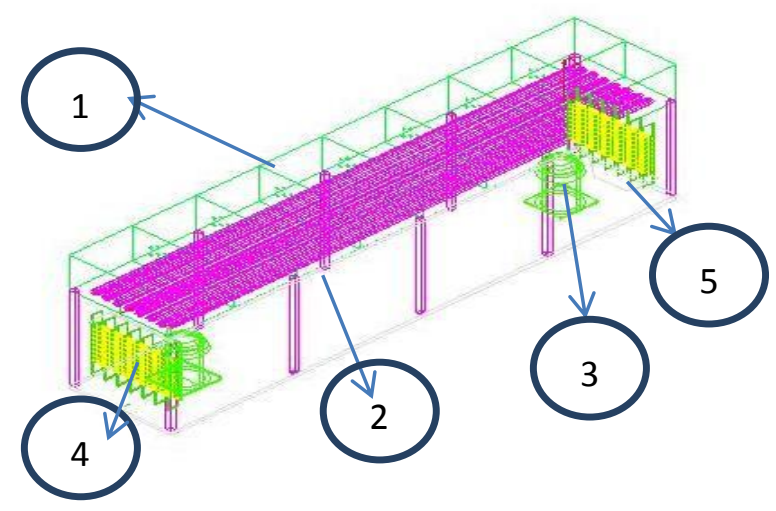

Gambar 2. Desain meja penjaja ikan

Figure 2. Design of higienis table reseller Sumber: Hasil desain

Keterangan Gambar:

1. Meja penjaja ikan

2. Evaporator

3. Kondensor

4. Kompresor

5. Pipa kapiler

Spesifikasi teknis unit pendingin meja penjaja ikan:
$\checkmark$ Kompresor
$\checkmark$ Pipa inlet kompresor
$\checkmark$ Pipa outlet kompresor
$\checkmark$ Pipa inlet evaporator
$\checkmark$ Pipa outlet evaporator
$\checkmark$ Pipa inlet kondensor
$\checkmark$ Pipa outlet kondensor
$\checkmark$ Fan
$\checkmark$ Pipa kapiler

Dari desain meja penjaja ikan higienis yang dibuat maka proses selanjutnya adalah diuji kinerjanya menggunakan beberapa tool berikut ini:

1.Simulasi menggunakan Guntner 2013, diperoleh ukuran spesifikasi evaporator sebagai berikut.

Tabel 1. Spesifikasi data evaporator

Table 1. Evaporator specification

\begin{tabular}{ll}
\hline Evaporator & GACC.031.ID27-AW.E \\
\hline Power consumption & $0,21 \mathrm{~kW}$ \\
\hline Length condenser & $1212 \mathrm{~mm}$ \\
\hline Width condenser & $430 \mathrm{~mm}$ \\
\hline Height condenser & $455 \mathrm{~mm}$ \\
\hline Inlet connection & $18 \mathrm{~mm}$ \\
\hline Out connection & $16 \mathrm{~mm}$ \\
\hline Sumber: Hasil pengolahan data
\end{tabular}

2.Simulasi menggunakan Guntner 2013, diperoleh ukuran spesifikasi kondensor sebagai berikut :

Tabel 2. Spesifikasi data kondensor

Table 2. Condenser specification

\begin{tabular}{ll}
\hline Condenser & GVM 035.1A/1NW.E \\
\hline Power consumption & $0,16 \mathrm{~kW}$ \\
\hline Length condenser & $610 \mathrm{~mm}$ \\
\hline Width condenser & $310 \mathrm{~mm}$ \\
\hline Height condenser & $460 \mathrm{~mm}$ \\
\hline Inlet connection & $9,5-10 \mathrm{~mm}$ \\
\hline Out connection & $9,5-10 \mathrm{~mm}$ \\
\hline
\end{tabular}

Sumber: Hasil pengolahan data

3.Simulasi menggunakan Danfoss $R S+3$, diperoleh ukuran spesifikasi kondensor sebagai berikut :

Tabel 3. Spesifikasi data kompresor Table 3. Compressor specification

\begin{tabular}{ll}
\hline Type & SC21/21G \\
\hline Code no & $104 \mathrm{G} 8180$ \\
\hline Compressor design & $\begin{array}{l}\text { Universal twin } \\
\text { compressor }\end{array}$ \\
\hline Refrigeran & $\mathrm{R} 134 \mathrm{a}$ \\
\hline Nominal voltage & $220-240$ \\
\hline Number of phases & 1 \\
\hline Maximum refrigeran charge & $2,20 \mathrm{~kg}$ \\
\hline Free gas volume & $2,920 \mathrm{~cm}^{3}$ \\
\hline Oil quantity & $1,220 \mathrm{~cm}^{3}$ \\
\hline Oil type & POE \\
\hline Sumber: Hasil pengolahan data &
\end{tabular}


4. Untuk pemilihan pipa kapiler menggunakan "Danfoss DanCap ${ }^{\mathrm{TM}}$ " dengan memasukkan parameter data sebagai berikut:

- Jenis refrigeran R134a

- Beban panas dari sistem 181,9 Btu/jam

- Temperatur evaporator $\left(-2^{0} \mathrm{C}\right)$

- Temperatur kondenser $\left(45^{\circ} \mathrm{C}\right)$

- Temperatur balik refrigeran ke kompresor $\left(11{ }^{\circ} \mathrm{C}\right)$.

Dari data-data tersebut diperoleh untuk panjang pipa kapiler $1810 \mathrm{~mm}$ maka diameter dalam pipa kapiler adalah $0,71 \mathrm{~mm}$.

5. Simulasi COP menggunakan solkane dengan memasukkan parameter sebagai berikut :
- refrigeran
$=\mathrm{R} 134 \mathrm{a}$
- temperatur evaporator $=-2{ }^{0} \mathrm{C}$
- $\quad$ superheating
$=5 \mathrm{~K}$
- kapasitas Refrigeran $=3 \mathrm{~kW}$
- temperatur kondensor $=45^{\circ} \mathrm{C}$
- subcooling
$=5 \mathrm{~K}$
- efisiensi
$=0,773 \%$

Hasil simulasi solkane menunjukkan nilai COP sebesar 3,65 , volume capacity $1861 \mathrm{kj} / \mathrm{m}^{3}$, pressure ratio 4,26 .

Diagram pressure-enthalphy (p-h) dari hasil analisis solkane dapat dilihat pada Gambar 3 dan nilai dari enthalphy dari siklus p-h dapat dilihat pada Tabel 4.

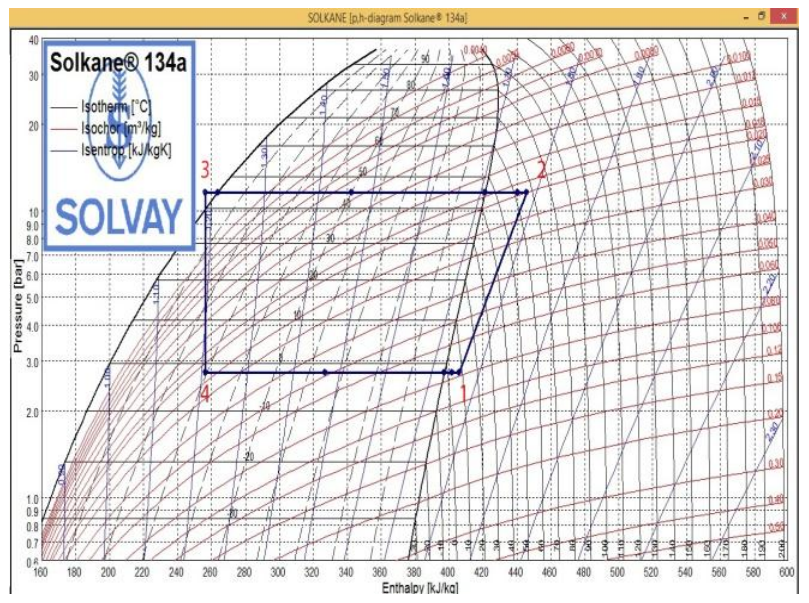

Gambar 3. Diagram p-h

Figure 3. $p$-h diagram of refrigeran system Sumber: Hasil pengolahan data
Proses dari diagram $\mathrm{p}$-h sebagai berikut:

1. Proses 1-2: merupakan kompresi kering superheating yang berlangsung didalam kompresor. Kerja yang terjadi pada refrigeran selama langkah kompresi adalah hasil dari peningkatan entalpi refrigeran di dalam kompresor dan laju aliran refrigeran.

2. Proses 2-3: merubah wujud gas menjadi cair, proses ini terjadi pada alat penukar kalor kondensor. Panas yang dibuang ke lingkungan tergantung pada laju aliran refrigeran dan panas laten dari refrigeran.

3. Proses 3-4: refrigeran dalam wujud cair jenuh mengalir melalui katup expansi.

4. Proses 4-1: refrigeran dalam fasa campuran uap cair yang melalui evaporator. Panas yang diserap oleh evaporator tergantung pada laju aliran refrigeran dan panas laten dari refrigeran.

Tabel 4. Sifat-sifat termodinamika refrigeran 134a pada sistem meja pendingin higienis

Table 4. Properties of thermodynamic134a of hygienic table reseller system

\begin{tabular}{cccccc}
\hline & $\mathbf{P}$ & $\mathbf{T}$ & $\mathbf{V}$ & $\mathbf{h}$ & $\mathbf{s}$ \\
\hline Point & Bar & ${ }^{\circ} \mathrm{C}$ & $\mathrm{dm}^{3} / \mathrm{kg}$ & $\mathrm{Kj} / \mathrm{kg}$ & $\mathrm{Kj} / \mathrm{kgK}$ \\
\hline 1 & 2.72 & 8.00 & 78.06 & 406.07 & 1.7596 \\
\hline 2 & 11.60 & 66.86 & 19.98 & 445.85 & 1.7832 \\
\hline 3 & 11.60 & 45.00 & 17.36 & 421.44 & 1.7090 \\
\hline 4 & 2.72 & -2.00 & 22.51 & 256.43 & 1.2083
\end{tabular}

Sumber: Hasil pengolahan data

Keterangan:

$\mathrm{P}$ : Tekanan

$\mathrm{T}:$ Temperatur

$\mathrm{V}$ : Volume

h : Vapor enthalpy

s : Liquid entropy

Dari diagram p-h terlihat bahwa sifat-sifat termodinamika dari gas R134 a yang dipakai dalam desain sistem pendingin dihasilkan bahwa, sistem pendingin dari desain meja penjaja menghendaki temperatur $-2{ }^{\circ} \mathrm{C}$ sesuai level yang dikehendaki untuk mendinginkan ikan kembung. Entalpi di titik 4 tidak mengalami penurunan seiring dengan proses ekspansi di pipa kapiler (proses 3-4). Panjang pipa kapiler yaitu $1810 \mathrm{~mm}$ masih dapat diperpanjang agar nilai entalpinya bergeser ke kiri. Bahwa semakin rendah 
temperatur yang harus diturunkan maka COP sistem juga mengalami kenaikan.

Dari desain temperatur yang harus diturunkan adalah dari $45{ }^{0} \mathrm{C}$ menjadi $-2{ }^{0} \mathrm{C}$. Hal ini disebabkan karena adanya peningkatan kapasitas refrigerasi yang kenaikannya masih lebih signifikan dibandingkan dengan daya kompresi yang juga mengalami kenaikan, ditunjukkan pada proses 1-2 yang bergeser ke kanan. Sehingga kerja yang terjadi pada refrigeran selama langkah tekan hasil dari peningkatan entalpi refrigeran di dalam kompresor dan laju aliran refrigeran, maka sedapat mungkin selisih entalpi ini (proses 1-2/445,85406,07) dikurangi. Caranya, dapat dilakukan dengan mengurangi total beban pendinginan pada sistem pendingin meja penjaja ikan higienis. Di dalam desainnya, meja ini akan mendinginkan ikan kembung sebanyak 250 kilogram dan $1000 \mathrm{~m}^{3}$ air secara bersamaan.

Kondisi ini dapat terlihat pada titik 1 dimana laju aliran refrigeran meningkat dengan signifikan $(78,06)$ yang menunjukkan panas yang diserap oleh evaporator menunjukkan besarnya laju aliran refrigeran dan panas laten dari refrigeran.

\section{KESIMPULAN DAN SARAN}

Dari hasil perhitungan maka dapat disimpulkan bahwa nilai COP untuk sistem pendingin meja penjaja ikan higienis adalah 3,65 dengan total beban pendinginan $3 \mathrm{~kW}$. Nilai COP yang tinggi disebabkan tuntutan temperatur evaporator yang rendah $\left(-2{ }^{0} \mathrm{C}\right)$ untuk total beban pendinginan 250 kilogram ikan dan $1000 \mathrm{~m}^{3}$ air secara bersamaan.

Peralatan sistem pendingin yang direncanakan adalah: kompresor SC21/21G, kondensor GVM/NW, evaporator GACC/AW.E, pipa kapiler dengan diameter $0,71 \mathrm{~mm}$. COP 3,65 telah mengacu SNI 03-6572-2001 tentang refrigerasi dimana COP minimum dari suatu sistem refrigerasi berkisar antara 2,3 sampai dengan 5,20. Maka desain sistem refrigerasi ini dapat digunakan.

\section{DAFTAR PUSTAKA}

Pengkondisian Udara pada Bangunan Gedung. SNI 03-6572-2001. Jakarta.

Daniel, D. (2011). Palkah Pendingin Tenaga Matahari. Laporan Akhir Penelitian. Pusat Pengkajian dan Perekayasaan Teknologi Kelautan dan Perikanan, Badan Penelitian dan Pengembangan Kelautan dan Perikanan. Kementerian Kelautan dan Perikanan. Jakarta.

Handoyo dan Lukito. (2002). Analisis pengaruh pipa kapiler yang dililitkan pada line suction terhadap performansi mesin pendingin. Jurnal Teknik Mesin, 4(2), 94-98.

Ilyas, S. (1983). Teknologi Refrigerasi Hasil Perikanan Jilid 1 Teknik Pendingin Ikan. Badan Penelitian dan Pengembangan Pertanian. Jakarta: CV Paripurna.

Marwan, E. (2005). Usaha peningkatan prestasi freezer dengan melilitkan pipa kapiler pada line suction. Seminar Nasional Efisiensi dan Konservasi Energi (FISERGI).

Prasetya, B.H.P., dan Putra, A.B.K. (2013). Studi experiment variasi laju pendinginan kondensor pada mesin pendingin defuse absorbi R22-DMF. Jurnal Teknik Pomits, 2(1), 2337-3539.

Radha, K.K, Sarada, S.N, dan Rajagopal, K. (2012). Development of a chest freezer - optimum design of an evaporator coil. International Journal of Automotive and Mechanical Engineering (IJAME), Vol. 5, 597-611.

Raharjo, S. (2011). Efektifitas penggunaan musicool pada mesin AC. Traksi, 11(1), 49-55.

Sjarif, B., Suwardiyono dan Gautama, S.D. (2010). Penangkapan dan Penanganan Ikan Tuna Segar di Kapal Rawai Tuna. Semarang: Balai Besar Pengembangan Penangkapan Ikan.

Soegeng, W. (2009). Uji prestasi mesin pendingin menggunakan refrigeran LPG. Jurnal Austenit, (1)2, 63-69.

Suherman, M. dan Gunawan, B. (1999). Palka Berinsulasi untuk Penanganan Ikan Segar Pada Perahu Motor Nelayan Kepulauan Seribu DKI Jakarta. Makalah disajikan dalam Lokakarya Non Peneliti.

Tampubolon, D. dan Samosir, R. (2005). Pemahaman tentang refrigerasi. Jurnal Teknik SIMETRIKA, (4)1, 312-316. 